\title{
Randomized clinical trial of the effect of NovaMin and CPP-ACPF in combination with dental bleaching
}

\section{Abstract}

\section{Larissa Dias ALEXANDRINO}

Cristiane de Melo ALENCAR 1

Ana Daniela Silva da SILVEIRA ${ }^{1}$

Eliane Bemerguy ALVES ${ }^{1}$

Cecy Martins SILVA ${ }^{1}$
Submitted: October 27, 2016 Accepted: December 29, 2016
Objective: This randomized, controlled, double-blind clinical study evaluated the effect of calcium sodium phosphosilicate (NovaMin) and casein phosphopeptide-amorphous calcium phosphate with fluoride (CPP-ACPF) on the prevention of post-operative sensitivity and on the effects of clinical bleaching treatment. Material and Methods: Sixty volunteers were selected according to inclusion and exclusion criteria and were randomly assigned into three groups $(n=20)$ : CG (control group) patients, who were treated with $35 \%$ hydrogen peroxide; NOVAG (NovaMin group) patients, who were treated with 35\% hydrogen peroxide followed by the application of NovaMin; and CPPG (CPP group) patients, who were treated with $35 \%$ hydrogen peroxide followed by the application of CPP-ACPF. Both bioactive agents were applied for five minutes. An evaporative stimulus associated with a modified visual scale was used to analyze sensitivity 24 hours after each bleaching session. The color evaluation was performed on the maxillary central incisors using a spectrophotometer. Associations between the intervention group, bleaching session, and reported sensitivity were tested using Chi-square partitioning. Results: Color change values $(\triangle \mathrm{E})$ were analyzed using analysis of variance (ANOVA). The significance level used for both tests was $5 \%$. In the intragroup assessment, the Friedman test showed that only the CPP-ACPF group showed no statistically significant difference $(p<0.05)$ between baseline and first bleaching session. In the intergroup assessment, the Kruskal-Wallis test showed that the CPPG had less postoperative sensitivity after the first session, when compared to the other groups $(p<0.05)$. Color change analysis $(\Delta E)$ showed a significant difference between the means obtained in the different bleaching sessions in all groups $(p<0.05)$. Conclusions: This study showed that the combination of CPP-ACPF with 35\% hydrogen peroxide significantly reduced post-operative sensitivity in the first session, compared with the other evaluated treatments. The association of CPP-ACPF and NovaMin did not affect the color change induced by tooth bleaching.

Keywords: Dentin sensitivity. Tooth bleaching. Dentin desensitizing agents.
Corresponding address: Cecy Martins Silva

R. Augusto Correa, n. 1 - Guamá Belém - PA - Brazil 66075-110 - Phone: +559132521269 e-mail: cecymsilva@gmail.com
${ }^{1}$ Universidade Federal do Pará, Belém, PA, Brasil. 


\section{Introduction}

Tooth bleaching has become a popular approach because it is conservative and capable of changing tooth color ${ }^{26}$. The use of highly concentrated agents is preferred by many dentists in clinical practice because it affords the professional greater control, ensures greater patient safety, and requires fewer applications ${ }^{24}$. Bleaching agents have an oxidizing action that leads to the formation of free radicals, reactive oxygen species, and hydrogen peroxide ions. These reactive molecules attack chromophores, causing their degradation and resulting in a bleaching effect ${ }^{29}$.

The most common adverse effect resulting from bleaching is dentinal sensitivity ${ }^{5}$, which is characterized by the manifestation of acute, short-term, or transient pain ${ }^{16}$. Moreover, it is currently believed that oxygen bubbles are formed in the dentinal tubules during the application of peroxides and that these bubbles can move the intratubular fluid and activate intradental nerves, causing post-operative sensitivity ${ }^{7}$. This hypothesis therefore suggests that sensitivity after bleaching is a consequence of peroxide penetration into the internal tooth structure, causing the direct activation of neuronal receptors ${ }^{18}$.

Although saliva has a known remineralizing action ${ }^{9}$, it alone may not be able to increase the levels of available calcium and phosphate in the oral cavity and prevent the incidence of sensitivity ${ }^{27}$. To minimize or eliminate post-operative sensitivity, fluorides and/or remineralizing solutions have been used to maintain a positive balance between demineralization and remineralization ${ }^{3}$. Bioactive agents containing calcium and phosphorus ions have thus been used to treat dentinal hypersensitivity ${ }^{12}$. In the presence of saliva and biofilm, these ions can occlude the dentinal tubules and reduce nerve-ending excitability without affecting the tooth bleaching process ${ }^{25}$.

Calcium sodium phosphosilicate (NovaMin) and casein phosphopeptide-amorphous calcium phosphate with fluoride (CPP-ACPF) are bioactive products that have been used to promote enamel remineralization ${ }^{17,20}$, and they were therefore combined with bleaching treatments in this study.

An inorganic bioactive glass, known commercially as NovaMin, has also been used for treating dental hypersensitivity and for enamel remineralization. This material was originally developed to act on bone regeneration because it has a ceramic structure containing amorphous calcium and sodium. NovaMin is therefore a highly water-reactive phosphosilicate composed of fine powder particles that can physically obstruct the dentinal tubules ${ }^{11}$.

NovaMin is composed of sodium, phosphate, calcium, and silica, and it quickly releases calcium, phosphorus, and sodium ions when forming the hydroxyapatite layer ${ }^{10}$. NovaMin forms an amorphous layer rich in the ionic compound $\mathrm{a}_{2}+3 \mathrm{PO}^{4-}$, which is crystallized by the incorporation of $\mathrm{OH}^{-}$and $3 \mathrm{CO}^{2-}$ anions present in the solution, thereby remineralizing the tissue ${ }^{30}$.

Despite promising results in other areas, it is believed that the use of remineralizing bioactive agents to accelerate the remineralization process may impair the enamel's permeability and consequently impair the quality of the bleaching treatment. The penetration of reactive oxygen species and free radicals may be prevented by the deposition of ionic crystals on the tooth surface ${ }^{6}$.

The various commercial bioactive compounds vary widely in their clinical efficacy; thus, clinical studies are necessary to confirm the effectiveness of these substances when associated with bleaching.

This randomized clinical trial aimed to evaluate the effect of two bioactive agents, NovaMin and CPPACPF, used after tooth bleaching, on the prevention of post-operative sensitivity and on the quality of the bleaching treatment. The null hypotheses tested in this study were as follows: H01 - there is no difference in post-operative sensitivity between the tested groups (control, NovaMin, and CPP-ACPF) at the different evaluation times; $\mathrm{HO}$ - there is no difference between the tested groups (control, NovaMin, and CPP-ACPF) regarding color change $(\Delta \mathrm{E})$ at the different evaluation times.

\section{Material and Methods}

\section{Ethical aspects}

The study followed the guidelines published by the Consolidated Standards of Reporting Trials CONSORT $^{22}$. The Research Ethics Committee of the Health Sciences Institute, Federal University of Para, reviewed and approved the study. The clinical trial number in the Brazilian Registry of Clinical Trials (REBEC) is U1111-1157-3105. 


\section{Population and sample calculation}

The software BioEstat ${ }^{\circledR}$ (Civil Society Mamirauá, AM, Brazil) was used to calculate the sample size using data from a pilot study, which was conducted with ten volunteers and that followed the same procedures as this study. A statistical power of $80 \%$, an a error of $5 \%$, and a sample loss prediction of $20 \%$ at the end of the study were considered for sample size calculation. The sample calculated for this study was of 20 patients per group, totaling 60 patients.

\section{Study design}

This randomized, controlled, double-blind study with three parallel arms evaluated comparatively the performance of bioactive agents recently proposed for reducing dentinal sensitivity after bleaching treatment. Sixty volunteers were selected according to the inclusion and exclusion criteria (Figure 1) and were divided into three groups by simple randomization $(n=20)$. All groups underwent the same bleaching treatment. The gum tissue adjacent to the whitened teeth was isolated using a polymerized resinous gum barrier (Top Dan - FGM; J oinville, SC, Brazil). Thirtyfive percent hydrogen peroxide (Whiteness HP - FGM; J oinville, SC, Brazil) was applied to the buccal surfaces of the incisors, canines, and premolars of both arches of the volunteers for 45 minutes. The bleaching treatment was performed over a total of three sessions, with an interval of seven days between them.

Patients in the experimental groups received an application of bioactive agents with a disposable applicator (Microbrush - Vigodent; J oinville, SC, Brazil) for five minutes on the bleached tooth surfaces after

\begin{tabular}{|l|}
\hline \multicolumn{1}{|c|}{ Inclusion Criteria } \\
\hline - Age between 18 and $26 ;$ \\
\hline - Good general and oral health conditions; \\
\hline - All anterior teeth healthy; \\
\hline - Initial color of A2 or darker according to the VITA scale; \\
\hline - pH and salivary flow within normal parameters; \\
\hline \multicolumn{1}{|c|}{ Exclusion Criteria } \\
\hline Previous tooth bleaching; \\
\hline - Restorations in the anterior teeth; \\
\hline - Pregnant or breast feeding; \\
\hline - Teeth darkened by tetracycline staining, fluorosis; teeth treated \\
endodontically; \\
\hline - Bruxism or exposed dentin on the incisal surface; \\
\hline - Non-carious cervical lesions; \\
\hline - Dentinal hypersensitivity. \\
\hline
\end{tabular}

Figure 1- Inclusion and exclusion criteria each bleaching session. The bioactive agents were later removed with water jets. Patients in the NOVAG (NovaMin group) were treated with NovaMin Repair and Protect (GSK Sensodyne; Brentford, Middlesex, United Kingdom), and patients in the CPPG (CPP group) were treated with CPP-ACPF (GC MI Paste Plus - Recaldent ${ }^{\circledR}$; Hasunuma-Cho, Itabashi-Ku, Tokyo, Japan).

All patients received oral hygiene kits containing a toothbrush (Oral B Indicator; São Paulo, SP, Brazil) and toothpaste with 1,450 ppm fluoride (ColgatePalmolive Company; São Paulo, SP, Brazil), along with instructions to use them three times per day.

The post-operative sensitivity evaluation was performed 24 hours after each bleaching session. An evaporative test was performed by applying air jets with a triple syringe (Dabi Atlante; Ribeirão Preto, SP, Brazil) to the labial surface of the bleached teeth. The volunteers received a modified visual scale (printed) containing facial expressions showing different levels of sensitivity and discomfort caused by the bleaching treatment (absent, mild, moderate, or severe).

The color evaluation was performed on each volunteer's upper incisors using an Easyshade Advance spectrophotometer (Easyshade; Vita Zahnfabrik, Bad Säckingen, Germany) with the CIE L*a*b* system, where the color change values $(\Delta \mathrm{E})$ were obtained for each group of teeth using the following formula: $\Delta \mathrm{E}=\left\{(\Delta \mathrm{L})^{2}+(\Delta \mathrm{a})^{2}+(\Delta \mathrm{b})^{2}\right\}^{1 / 2}$, where $\Delta \mathrm{L}^{*}=\mathrm{L}^{*}-\mathrm{L}^{*}{ }_{0}$; $\Delta \mathrm{a} *=\mathrm{a} *-\mathrm{a} *{ }_{0}$; and $\Delta \mathrm{b} *=\mathrm{b} *-\mathrm{b} *{ }_{0}$. The color evaluation was performed four times: before the bleaching treatment (baseline), and 24 hours after each of the three bleaching sessions.

To standardize the color measurement point on each tooth, a mold was made of each patient's upper arch, and a plaster model was obtained to construct a polyethylene plate with the aid of a laminator. When the mold was ready, fixed reference points were established using a perforation in the central region of the labial surface of the maxillary central incisors of each model, with a size corresponding to the spectrophotometer tip ${ }^{4}$.

\section{Statistical analysis}

The color change values $(\Delta E)$ for each group of studied teeth and the sensitivity reported by the volunteers were tabulated in an Excel spreadsheet (Microsoft Windows 2007) and analyzed using the program BioEstat ${ }^{\circledR}$. The association between the intervention group, the bleaching session, and the 
sensitivity reported after 24 hours was tested by analysis of variance (Friedman or Kruskal-Wallis). The $\Delta \mathrm{E}$ values obtained for each intervention group and each time point were analyzed using analysis of variance (ANOVA) followed by Tukey's test. The significance level adopted in all analyses was $5 \%$.

\section{Results}

Of the 60 randomized volunteers, 51 completed the treatment. Therefore, at the end of the study, 17 volunteers were evaluated in each experimental group (Figure 2). Table 1 shows the results for the evaluation of sensitivity reported by patients 24 hours after each bleaching session.

In the intragroup assessments, the Friedman test showed that only the CPP-ACPF group presented no statistically significant difference $(p>0.05)$ between baseline and first bleaching session. In the intergroup assessments, the Kruskal-Wallis test showed that the CPP-ACPF group had less post-operative sensitivity after the first session, compared with the other groups $(p<0.05)$.

The $\Delta \mathrm{E}$ values for the upper incisors were used to compare the color changes between the experimental groups at each bleaching session (Table 2 ).

The data analysis in Table 2 reveals that the variation in $\Delta \mathrm{E}$ was homogeneous between the groups; there was no significant difference $(p>0.05)$ when comparing the experimental groups at each treatment session. These data show that, under the conditions of this study, the groups treated with NovaMin and CPPACPF followed the same pattern of the control group, with $\Delta \mathrm{E}$ increasing up to the third session and with color stabilization after this point.

In addition, when analyzing the groups individually, a clear increase was observed in the $\Delta \mathrm{E}$ value at the end of the experiment in all tested groups. Both CG and CPPG groups showed an increase in $\triangle \mathrm{E}$ after the second bleaching session ( $p<0.05)$; however, this color difference was only observed after the third bleaching session in the NOVAG.

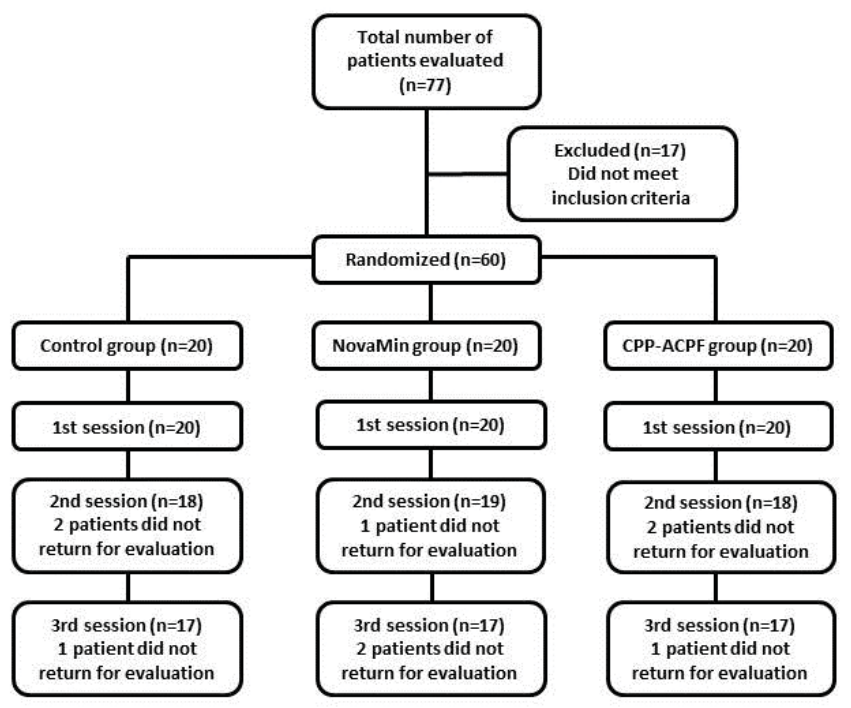

Figure 2- Schematic study design

Table 1- Median (Md) and interquartile ranges (IQR) of sensitivity described by patients after bleaching treatment, according to experimental group and session

\begin{tabular}{cccc}
\hline Time/ & Group 1 (control) & Group 2 (NovaMin) & Group 3 (CPP-ACPF) \\
\hline Groups & Md $( \pm \mathrm{IQR})$ & Md $( \pm \mathrm{IQR})$ & Md $( \pm \mathrm{IQR})$ \\
Baseline & $0.0( \pm 0.0)^{\mathrm{A}, \mathrm{a}}$ & $0.0( \pm 0.0)^{\mathrm{A}, \mathrm{a}}$ & $0.0( \pm 0.0)^{\mathrm{A}, \mathrm{a}}$ \\
$1^{\text {st }}$ session & $1.0( \pm 0.0)^{\mathrm{B}, \mathrm{a}}$ & $1.0( \pm 0.0)^{\mathrm{B}, \mathrm{a}}$ & $0.5( \pm 1.0)^{\mathrm{A}, \mathrm{b}}$ \\
$2^{\text {nd }}$ session & $1.0( \pm 0.0)^{\mathrm{B}, \mathrm{a}}$ & $1.0( \pm 0.0)^{\mathrm{B}, \mathrm{a}}$ & $1.0( \pm 0.0)^{\mathrm{B}, \mathrm{a}}$ \\
$3^{\text {rd }}$ session & $1.0( \pm 1.0)^{\mathrm{B}, \mathrm{a}}$ & $1.0( \pm 1.0)^{\mathrm{B}, \mathrm{a}}$ & $1.0( \pm 0.0)^{\mathrm{B}, \mathrm{a}}$ \\
\hline
\end{tabular}

Note1: Equal letters for similar values $(p>0.05)$ and different letters statistically different values $(p<0.05)$.

Note $^{2}$ :Capitalization is the comparison in the same column by Friedman test for comparisons intra groups; lower case letters representing the comparison on the same line by Kruskal-Wallis test for comparisons intergroup. 
Table 2- Means, standard deviations, and $95 \%$ confidence intervals of $\Delta \mathrm{E}$ values of the upper incisors, according to experimental group and session

\begin{tabular}{|c|c|c|c|c|c|c|}
\hline \multirow[t]{2}{*}{ Time/Groups } & \multicolumn{2}{|c|}{ Group 1 (control) } & \multicolumn{2}{|c|}{ Group 2 (NovaMin) } & \multicolumn{2}{|c|}{ Group 3 (CPP-ACPF) } \\
\hline & $( \pm S D)$ & $\mathrm{Cl}(95 \%)$ & $( \pm S D)$ & $\mathrm{Cl}(95 \%)$ & ( $\pm S D)$ & $\mathrm{Cl}(95 \%)$ \\
\hline $1^{\text {st }}$ session & $4.57( \pm 1.77)^{\mathrm{A}, \mathrm{a}}$ & $3.66-5.48$ & $4.64( \pm 3.01)^{\mathrm{A}, \mathrm{a}}$ & $3.09-6.19$ & $5.13( \pm 1.35)^{\mathrm{A}, \mathrm{a}}$ & $4.44-5.83$ \\
\hline $2^{\text {nd }}$ session & $7.63( \pm 1.55)^{\mathrm{B}, \mathrm{a}}$ & $6.83-8.43$ & $6.64( \pm 2.90)^{\mathrm{B}, \mathrm{a}}$ & $5.15-8.13$ & $7.35( \pm 2.38)^{\mathrm{B}, \mathrm{a}}$ & $6.12-8.57$ \\
\hline $3^{\text {rd }}$ session & $10.46( \pm 1.60)^{\mathrm{C}, \mathrm{a}}$ & $9.64-11.28$ & $9.60( \pm 3.24)^{c, a}$ & $7.93-11.27$ & $9.87( \pm 1.75)^{\mathrm{C}, \mathrm{a}}$ & $8.97-10.77$ \\
\hline 24 hours & $9.84( \pm 2.60)^{\mathrm{c}, \mathrm{a}}$ & $8.50-11.18$ & $10.10( \pm 3.98)^{\mathrm{C}, \mathrm{a}}$ & $8.06-12.15$ & $9.85( \pm 2.17)^{\mathrm{C}, \mathrm{a}}$ & $8.73-10.96$ \\
\hline
\end{tabular}

Note $^{1}$ : Same letters for similar values $(p>0.05)$ and different letters for significantly different values $(p<0.05)$.

Note $^{2}$ : Upper case letters represent comparisons between rows in the same column; lower case letters represent comparisons between columns in the same row by analysis of variance (ANOVA) followed by Tukey's test.

\section{Discussion}

Hydrogen peroxide at a 35\% concentration has a high capacity of penetrating the enamel and dentin because of its low molecular weight (34.0147 g/mol), as well as its ability to denature protein, increase ionic movement, and stimulate nerve receptors. These factors together explain the high incidence of tooth sensitivity ${ }^{2}$.

Most post-bleaching sensitivity prevention treatments are based on the use of desensitizing agents, where the proposed mode of action is nerve inhibition and/or depolarization ${ }^{23}$. According to Paula, et al. ${ }^{19}$ (2013), the use of desensitizing agents has produced better results than the use of painkillers and anti-inflammatory agents. Furthermore, prior studies claim that bioactive products with tubular occlusion activity can preserve dental tissue by forming a protective layer over the enamel ${ }^{14}$.

The null hypothesis ( $\mathrm{HO1}$ ) of this study was rejected because we observed that post-operative sensitivity was significantly reduced in the CPPG. The groups differed in tooth sensitivity 24 hours after the first bleaching session. Only the CPPG volunteers reported a lack of sensitivity, while most members of the CG and NOVAG presented mild pain, not differing significantly from each other. These results can be explained by the action of CPP-ACPF, which acts as a calcium and phosphate carrier that transports these minerals to the tooth surface, promoting their supersaturation. Additionally, the presence of casein in this compound stabilizes calcium phosphate by changing the chemical structure of the tooth surface and promoting remineralization ${ }^{28}$.

Reynolds, et al. ${ }^{21}$ (2001) report that CPP-ACP attaches easily to the tooth surface and to the plaque bacteria surrounding the tooth. Therefore, the CPP-ACP deposits are formed in close proximity to the tooth surface. These authors hypothesized that, in acidic conditions, CPP-ACP promotes the formation of calcium ions and free phosphates, substantially increasing calcium phosphate levels in the plaque. This effect would thus maintain a state of supersaturation that inhibits enamel demineralization and promotes remineralization, explaining the results of our study.

By contrast, NovaMin only reduced post-operative sensitivity in the first session. This short-term effect is due to the rapid precipitation capacity of calcium and phosphate ions, leading to a more immediate occlusion of dentinal tubules ${ }^{1}$. These glasses form an integrated bond with hard tissue through the formation of a carbonated hydroxyapatite layer on tissue surfaces following immersion in physiological solutions ${ }^{13}$. This hydroxyapatite layer, in turn, is generally thought to help protein binding, leading to the formation of a tight bond with the enamel ${ }^{8}$. Therefore, further studies must be conducted to evaluate the dissolution mechanism of NovaMin.

Instrumental evaluation is preferred to visual assessment, because the former provides the most practical and statistically reliable process, enabling analysis in small areas. Color evaluation using a spectrophotometer is performed under the International Commission on Illumination ( $\mathrm{CIE}$ ) standardization, in which the $L^{*}, a^{*}$, and $b^{*}$ coordinate values of each tooth, referring to black and white (luminosity), redgreen and blue-yellow variations, respectively, are evaluated. These measurements thereby allow a total color variation to be calculated $(\Delta E)$. $A \Delta E$ variation of 3.3 to 3.7 is clinically apparent after tooth bleaching, which is in line with our results ${ }^{15}$.

The second null hypothesis ( $\mathrm{HO2}$ ) was accepted based on the results of this color change evaluation method. The color evaluation results of this study showed that the color changes in the groups treated with NovaMin and CPP-ACPF followed a pattern similar to that observed in the $C G$, with an increase in $\triangle E$ up to the third session. These results show that the substances used to prevent sensitivity did not compromise tooth 
bleaching.

The CPP-ACP associated with $0.2 \%$ fluoride (900 ppm) may have promoted not only remineralization, but also the formation of a more homogeneous enamel layer, which is less permeable to pigments derived from the diet. By contrast, the high solubility of the ionic layer formed by the NovaMin bioactive likely compromised the longevity of the bleaching treatment in this experimental group.

The results suggest that, under the examined conditions, tooth bleaching with CPP-ACPF causes less sensitivity in treated teeth than a bleaching agent alone or a bleaching agent plus NovaMin. None of the bioactive agents affected the tooth bleaching process.

\section{Conclusion}

The combination of CPP-ACPF with a bleaching treatment significantly reduced post-operative sensitivity in the first week, when compared with a bleaching treatment without a bioactive agent. The combination of NovaMin with bleaching treatment produced results similar to those obtained with bleaching treatment without a bioactive agent, and the association of either CPP-ACPF or NovaMin with $35 \%$ hydrogen peroxide did not affect the bleaching process.

\section{Acknowledgments}

The authors thank CNPq - National Council for Scientific and Technological Development.

\section{References}

1- Ballard RW, Hagan J L, Phaup AN, Sarkar N, Townsend JA, Armbruster PC. Evaluation of 3 commercially available materials for resolution of white spot lesions. Am J Orthod Dentofac Orthop. 2013; 143: S78-84. 2- Bernardon JK, Sartori N, Ballarin A, Perdigão J, Lopes GC, Baratieri LN. Clinical performance of vital bleaching techniques. Oper Dent. 2010; 35:3-10.

3- Besinis A, Van Noort R, Martin N. Remineralization potential of fully demineralized dentin infiltrated with silica and hydroxyapatite nanoparticles. Dent Mater. 2014; 30:249-62.

4- Bizhang $M$, Chun $Y H$, Damerau $K$, Singh $P$, Raab WH, Zimmer S. Comparative clinical study of the effectiveness of three different bleaching methods. Oper Dent. 2009; 34:635-41.

5- Caviedes-Bucheli J, Ariza-Garcia G, Restrepo-Mendez S, Ríos-Osoria $\mathrm{N}$, Lombana N, Munõz HR. The effect of tooth bleaching on substance $P$ expression in human dental pulp. J Endod. 2008;34:1462-5.

6- Chen HP, Chang CH, Liu JK, Chuang SF, Yang JY. Effect of fluoride containing bleaching agents on enamel surface properties. J Dent. 2008; 36: 718-25
7- Chidchuangchai W, Vongsavan N, Matthews B. Sensory transduction mechanisms responsible for pain caused by cold stimulation of dentine in man. Arch Oral Biol. 2007; 52:154-60

8- Claydon NC, Hall C, Hughes AJ, Shaw D, Seong J, Davies M, et al. Randomized controlled trial to study plaque inhibition in calcium sodium phosphosilicate dentifrices. J Dent. 2016;46:61-7.

9- Edgar WM, Higham SH, Manning RH. Saliva simulation and caries prevention. Adv Dent Res. 1994;8:9-45.

10- Elkassas D, Arafa A. Remineralizing efficacy of different calciumphosphate and fluoride based delivery vehicles on artificial caries like enamel lesions. J Dent. 2014;42:466-74.

11- Gjorgievska E, Nicholson JW. Prevention of enamel demineralization after tooth bleaching by bioactive glass incorporated into toothpaste. Aust Dent J. 2011;56:193-200.

12- Hamba H, Nikaido T, Inoue G, Sadr A, Tagami J. Effects of CPP-ACP with sodium fluoride on inhibition of bovine enamel demineralization: a quantitative assessment using micro-computed tomography. J Dent. 2011; 39: 405-13.

13- Hench LL. The story of bioglass. J Mater Sci Med. 2006; 17: 967-78. 14- Khoroushi M, Mazaheri H, Manoochehri A. Effect of CPP-ACP application on flexural strength of bleached enamel and dentin complex. Oper Dent. 2011; 36:372-9.

15- Marson FC, Sensi LG, Vieira LC, Araújo EC. Clinical evaluation of in-office bleaching dental treatments with and without the use of lightactivation. Oper Dent. 2008; 33:15-22.

16- Orchardson R, Gillam DG. Managing dentin hypersensitivity. J Am Dent Assoc. 2006; 137:990-8.

17- Oshiro M, Yamaquchi K, Takamizawa T, Inage $\mathrm{H}$, Watanabe T, Irokawa $A$, et al. Effect of CPP-ACP paste on tooth mineralization: an FE-SEM study. J Oral Sci. 2007; 49: 115-20

18- Park CK, Kim MS, Fang Z, Li HY, Jung SJ, Choi SY, et al. Functional expression of thermo-transient receptor potential channels in dental primary afferent neurons: implication for tooth pain. J Biol Chem. 2006; 281:304-11.

19- Paula E, Kossatz S, Fernandes D, Loguercio A, Reis A. The effect of preoperative ibuprofen use on tooth sensitivity caused by in-office bleaching. Oper Dent. 2013;38:601-8.

20- Rehder Neto FC, Maeda FA, Turssi CP, Serra MC. Potential agents to control enamel caries-like lesions. J Dent. 2009;37:786-90.

21- Reynolds EC. Anticariogenic complexes of amorphous calcium phosphate stabilized by casein phosphopeptides: a review. Spec Care Dentist. 2001; 18:8-16.

22- Schulz KF, Altman DG, Moher D, CONSORT Group. CONSORT 2010 statement: updated guidelines for reporting parallel group randomised trials. PLoS Med. 2010;24: e1000251.

23- Shiau HJ. Dentin hypersensitivity. J Evid Based Dent Pract. 2012; 12:220-8.

24- Sulieman M, Addy M, MacDonald E, Rees JS. The effect of hydrogen peroxide concentration on the outcome of tooth whitening: an in vitro study. J Dent. 2004; 32: 295-9.

25- Tay LY, Kose C, Loguercio AD, Reis A. Assessing the effect of a desensitizing agent used before in-office tooth bleaching. J Am Dent Assoc. 2009; 140: 1245-51.

26- Torres CR, Wiegand A, Sener B, Attin T. Influence of chemical activation of a $35 \%$ hydrogen peroxide bleaching gel on its penetration and efficacy - in vitro study. J Dent. 2010; 38:838-46.

27- Trushkowsky RD, Oquendo A. Treatment of dentin hypersensitivity. Dent Clin North Am. 2011;55:599-608

28- Wefel JS. NovaMin: likely clinical success. Adv Dent Res. 2009;21:403.

29- Woo J M, Ho S, Tam LE. The effects of bleaching time on dentin fracture toughness in vitro. J Esthet Restor Dent. 2010;22:179-85.

30- Yang H, Pei D, Chen Z, Lei J, Zhou L, Huang C. Effects of the application sequence of calcium-containing desensitising pastes during etch-and-rinse adhesive restoration. J Dent. 2014;42:1115-23. 